\title{
Quality of Life Improvement and Long-Term Effects of Peripheral Blood Mononuclear Cell Transplantation for Severe Arteriosclerosis Obliterans in Diabetic Patients on Dialysis
}

\author{
Junichi Hoshino, MD; Yoshifumi Ubara, MD; Shigeko Hara, MD; Yoko Sogawa, MD; \\ Tatsuya Suwabe, MD; Yasushi Higa, MD; Shohei Nakanishi, MD; Naoki Sawa, MD; \\ Hideyuki Katori, MD; Fumi Takemoto, MD; Yo Fujimoto, MD*; \\ Eiichi Ohta, MD**; Kanetoshi Ohara, MD**; Kenmei Takaichi, MD
}

\begin{abstract}
Background Severe arteriosclerosis obliterans (ASO) can be intractable, especially in diabetic patients on hemodialysis (HD). Recently, the transplantation of autologous peripheral blood mononuclear cells (PBMNCs) has been reported to have beneficial effects, but the long-term effects and impact on quality of life (QOL) have not been studied.

Methods and Results Autologous PBMNCs were transplanted into 7 diabetic patients on HD who had severe ASO ( 5 cases with Fontaine IV and 2 with Fontaine III) after administration of $5 \mu \mathrm{g} / \mathrm{kg}$ granulocyte colony stimulating factor; QOL and degree of ischemia was assessed by measuring skin temperature, skin perfusion pressure (SPP), ankle-brachial index (ABI), and ulcer size, and from angiographic findings. At 4 weeks after the procedure, skin temperature was significantly improved, and SPP and ABI also were increased. These beneficial effects persisted for up to 24 weeks. Angiographic findings and ulcer size improved in 3 of 7 and 3 of 4 patients, respectively. SF-36v2 analysis revealed significant improvements in pain scores. No serious complications were detected.

Conclusion Transplantation of PBMNCs resulted in improvement in pain and leg ischemia for over 6 months without serious complications. This therapy is safe and effective for severe ASO in diabetic patients on HD. (Circ J 2007; 71: 1193-1198)
\end{abstract}

Key Words: Arteriosclerosis obliterans; Diabetes mellitus; Dialysis; Peripheral blood mononuclear cell transplantation; Quality of life

$A$ teriosclerosis obliterans (ASO) is a disease that significantly impacts patients' quality of life (QOL) because of leg pain, ulceration, and gangrene. In most developed countries, the incidence of severe limb ischemia is estimated to be $50-100$ per 100,000 cases every year, but the number of patients needing medical treatment for severe limb ischemia will probably increase in the coming years because of the increasing prevalence of diabetes mellitus (DM) and hypertension, aging populations, and tobacco consumption. Current treatment options include medicines, such as anticoagulants and antiplatelet drugs, intravascular treatments, and bypass surgery. However, in patients with diffuse and distal peripheral severe stenosis, amputation of lower extremities is often required, especially in hemodialysis (HD) patients.

Recently, the use of mononuclear cells harvested from the bone marrow or peripheral blood mononuclear cells (PBMNCs) has been reported to improve limb ischemia in such patients, suggesting that this may be a therapeutic

(Received November 30, 2006; revised manuscript received April 2, 2007; accepted April 25, 2007)

Nephrology Center, *Cardiovascular Center and **Department of Plastic Surgery, Toranomon Hospital, Tokyo, Japan

Mailing address: Junichi Hoshino, MD, Nephrology Center, Toranomon Hospital, 2-2-2 Toranomon, Minato-ku, Tokyo 105-8470, Japan.

E-mail: hoshino@toranomon.gr.jp strategy for peripheral artery disease ${ }^{2-4}$ However, there are no reports of the long-term effects or changes in QOL after PBMNC transplantation for severe ASO in DM patients on HD, who are considered the high-risk group for limb ischemia and amputation. In this study, we examined 7 such patients who underwent autologous PBMNC transplantation for severe intractable ASO and evaluated the effectiveness, duration of effect of this therapy, the QOL, and any complications.

\section{Methods}

Of the DM patients on HD, those with allergy to granulocyte-colony stimulating factor (G-CSF), pregnant or breastfeeding, with malignancy, a history of leukemia within past 5 years, severe proliferative diabetic retinopathy, severe ischemic heart or cerebrovascular disease, unable to give fully informed consent, or a smoking history within the past 3 months, were excluded. After approval of the medical ethics committee of Toranomon Hospital, 7 severe intractable ASO patients with DM on HD gave fully informed consent and were enrolled (5 with Fontaine IV, and 2 with Fontaine III; 4 men, 3 women between 54 and 68 years old, mean, 63.6 \pm 4.5$)$ Characteristics of the patients are shown in Table 1. Every patient on HD (mean duration 7.6 6 6.0 years) was diagnosed with DM, and was taking anticoagu- 
Table 1 Patients' Characteristics

\begin{tabular}{ccccccc}
\hline \hline $\begin{array}{c}\text { Patient } \\
\text { no. }\end{array}$ & $\begin{array}{c}\text { Agel } \\
\text { gender }\end{array}$ & Fontaine & $\begin{array}{c}\text { HD duration } \\
\text { (years) }\end{array}$ & $\begin{array}{c}\text { Amputation } \\
\text { history }\end{array}$ & $\begin{array}{c}\text { Total cells } \\
\left(\times 10^{10} / \text { body }\right)\end{array}$ & $\begin{array}{c}\text { CD34 cells } \\
\left(\times 10^{7} / \text { body }\right)\end{array}$ \\
\hline 1 & $65 / M$ & III & 12 & - & $\times$ & 1.5 \\
2 & $64 / F$ & $\begin{array}{c}\text { IV (hand ulcer) } \\
\text { \& leg gangrene) }\end{array}$ & 2 & R below-knee \& 4 fingers & $\times$ & 0.1 \\
3 & $66 / M$ & IV (ulcer) & 10 & Labove-knee & $\times$ & 3.8 \\
4 & $64 / F$ & IV (ulcer) & 1.5 & L toe & 1.19 & 1.2 \\
5 & $64 / M$ & IV (gangrene) & 6 & L toe & 4.32 & 12.7 \\
6 & $54 / M$ & IV (ulcer) & 4 & L toe & 3.15 & 8.0 \\
7 & $68 / F$ & III & 18 & L below-knee & 1.58 & 1.2 \\
\hline
\end{tabular}

HD, hemodialysis; Total cells, implanted total mononuclear cells.

\section{Lower legs}

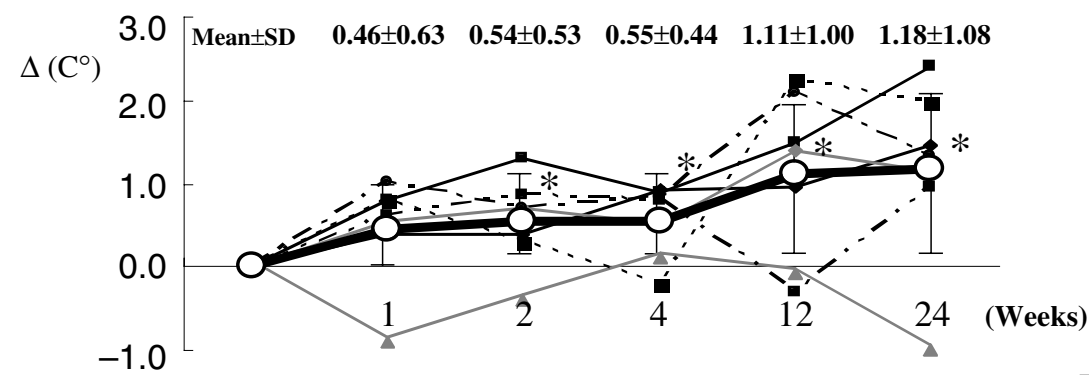

$\underline{\text { Toes }}$

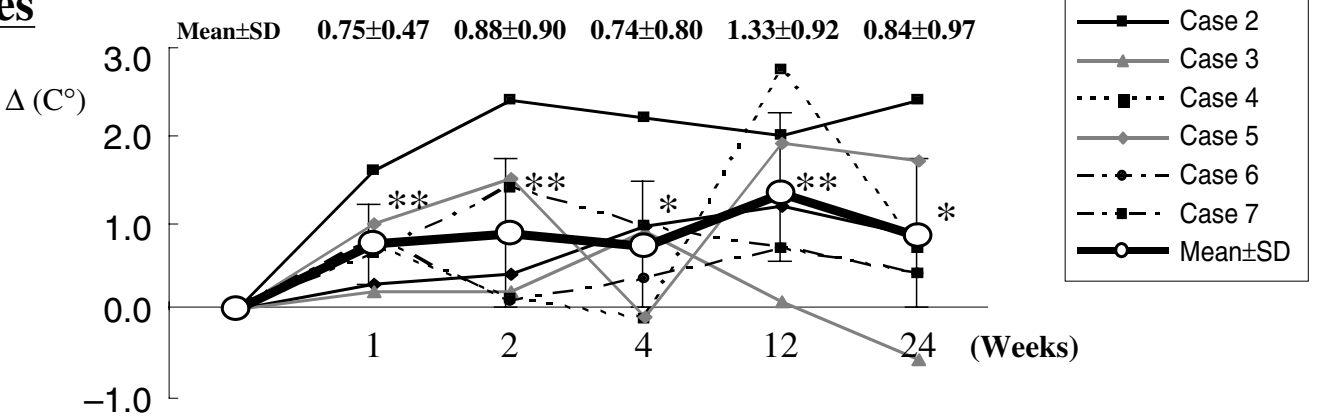

Fig 1. Skin temperature improved in 6 of 7 patients. Skin temperature in the lower legs and toes improved at each observational point with significance, even at 1 and 2 weeks after the treatment. The peak elevations of skin temperature were observed at 6 months after the treatment (end of the observation period) in the lower legs $\left(+1.18 \pm 1.08^{\circ} \mathrm{C}\right.$ ), and 3 months in the toes $\left(+1.33 \pm 0.92^{\circ} \mathrm{C}\right) . * \mathrm{p}<0.05 ; * * \mathrm{p}<0.01$, vs control (before the treatment)

lants, antiplatelet drugs, and prostaglandins for more than 3 months. We discussed treatment options for every patient by conference with cardiovascular specialists, nephrologists, plastic surgeons, and anesthesiologists. All patients were considered not amenable to surgical, intravascular, or other traditional treatments. Six of the 7 patients had histories of above- or below-knee or toe amputation. Anti-platelet agents, anticoagulants, and prostaglandins were continued during the pretreatment examination and follow-up, except for 1 week before the spinal anesthesia given at the time of transplantation.

\section{Protocol}

We diagnosed ASO by physical status and angiography, and assessed ischemic conditions by measuring the anklebrachial index (ABI), the toe-brachial pressure index (form PWV/ABI, Omron Colin, Tokyo), skin perfusion pressure (SPP) (PV2000, Kaneka, Osaka), and skin temperatures using thermal photography (Infraeye 1200A, Nihon Koden, Tokyo) under constant room temperature $\left(25.0 \pm 1.0^{\circ} \mathrm{C}\right)$ and humidity $(50.0 \pm 20.0 \%)$. The major and minor axes of skin ulcers were measured. These parameters were measured $0,1,2,4,12$, and 24 weeks after treatment, and compared with the pretreatment values.

The patients underwent digital subtraction angiography before and 1 month after treatment. The angiographic score (2) for the formation of new collateral vessels was assessed as +0 (no collateral development), +1 (slight), +2 (moderate), and +3 (rich) at the time at which contrast flow in the main conducting arteries was most clearly visible. To minimize body temperature bias, we performed measurements at a constant room temperature and humidity, after allowing the patient to rest in the room for $15 \mathrm{~min}$. Leg and toe temperatures were adjusted to forehead temperature to correct for differences in other conditions. SPP was measured on the day without HD and the value was adjusted by systemic pressure.

Patients' health-related QOL (HR-QOL) was evaluated by a questionnaire (SF-36 Health Survey, version 2 [SF-36v2]: SF-36 Medical Outcomes Trust) at 0 and 24 weeks after 


\section{Lower legs}

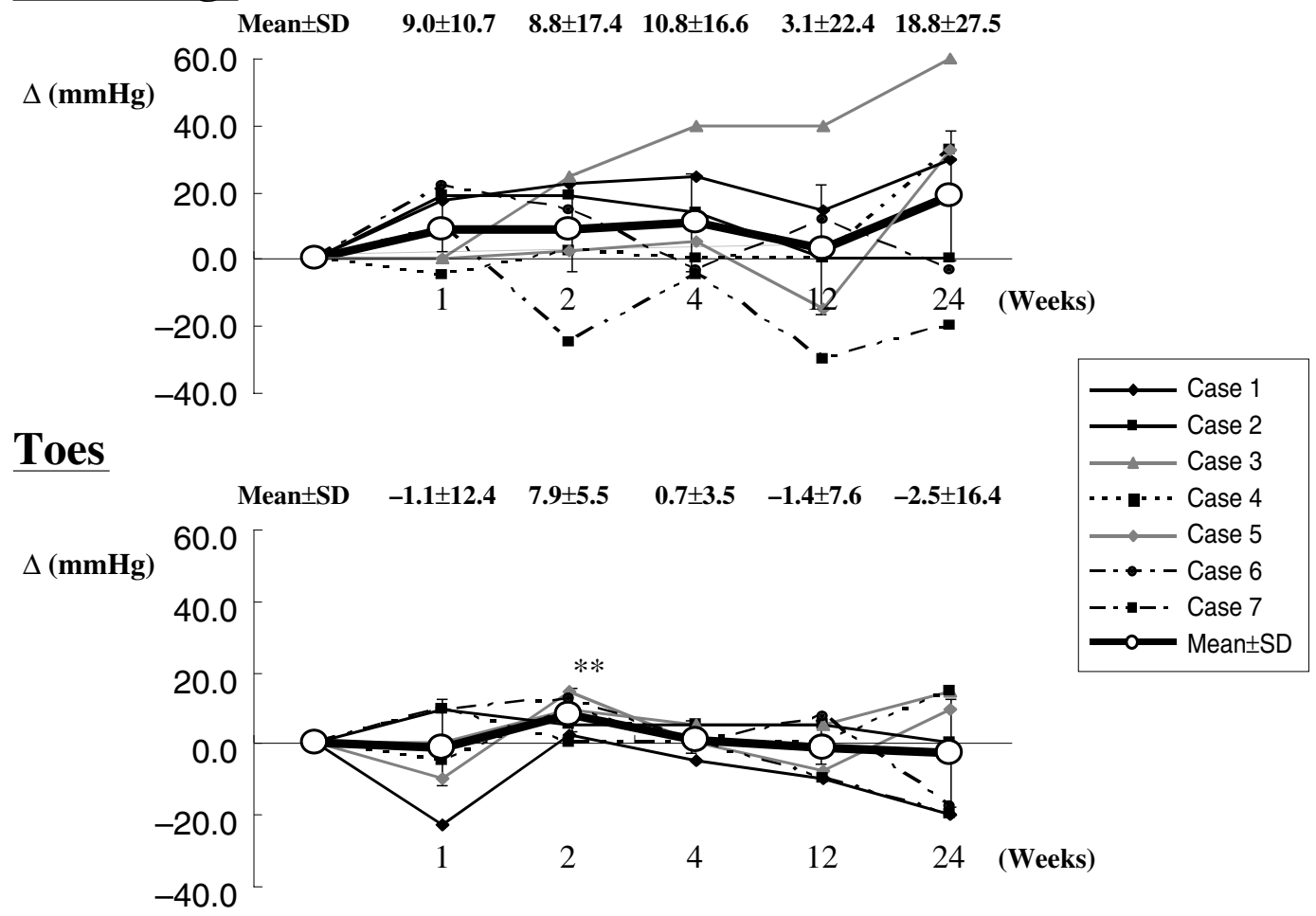

Fig 2. Skin perfusion pressures (SPP) in the lower legs improved more than $10 \mathrm{mmHg}$ in 4 of 7 patients, and less than $10 \mathrm{mmHg}$ in 1 of 7 patients. It also increased early after treatment, but did not show a significant change. SPP in the toes did not change significantly. ${ }^{*} \mathrm{p}<0.05 ; * * \mathrm{p}<0.01$, vs control (before the treatment).

\section{ABI changes}

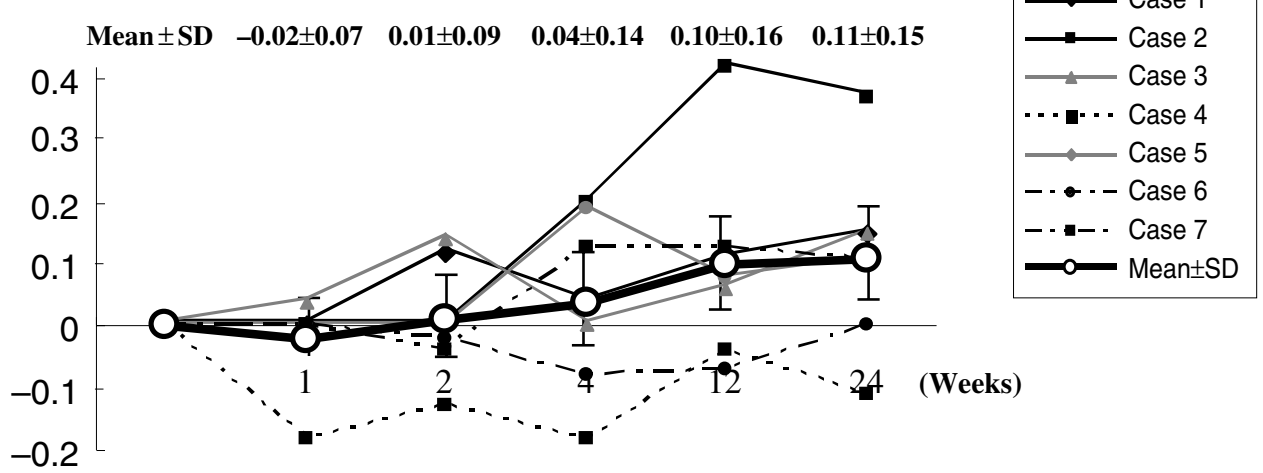

Fig 3. The ankle-brachial index (ABI) improved gradually after treatment. At the end of the observation period, 6 months, the peak elevation of $\mathrm{ABI}(+0.11 \pm 0.15)$ was seen and $\mathrm{ABI}$ improved more than 0.10 in 5 of 7 cases; however, it did not show a significant change.

treatment. The SF-36v2 health survey consists of 36 questions that evaluate 8 discrete areas: physical functioning, social functioning, bodily pain, general health perceptions, vitality, role limitations due to emotional problems (roleemotional), role limitations due to physical health problems (role-physical), and mental health. Analysis and scoring of SF-36v2 data were subjected to norm-based scoring to compare with a Japanese standard population according to guidelines developed by Fukuhara et al5

\section{Therapies}

After administration of $5 \mu \mathrm{g} \cdot \mathrm{kg}^{-1} \cdot$ day $^{-1}$ G-CSF (lenogras-
Table 2 Ulcer Size Changes After the Treatment

\begin{tabular}{clccc}
\hline \hline \multirow{2}{*}{$\begin{array}{c}\text { Patient } \\
\text { no. }\end{array}$} & \multicolumn{4}{c}{ Ulcer size changes $(\mathrm{mm})$} \\
\cline { 2 - 5 } & Before & 1 month & 3 months & 6 months \\
\hline 2 & $50 \times 30$ & $40 \times 25$ & $20 \times 12$ & $12 \times 8$ \\
3 & $10 \times 8$ & $0 \times 0$ & $0 \times 0$ & $0 \times 0$ \\
4 & $10 \times 6$ & $10 \times 5$ & $10 \times 5$ & $10 \times 5$ \\
6 & $20 \times 10$ & $5 \times 5$ & $0 \times 0$ & $0 \times 0$ \\
\hline
\end{tabular}

Ulcer size improved in 3 of 4 patients. Patient no. 3 and no. 6 improved completely within 2 weeks and 3 months, respectively. 
Table 3 Clinical Outcomes

\begin{tabular}{|c|c|c|c|c|c|c|c|c|}
\hline \multirow{2}{*}{$\begin{array}{c}\text { Patient } \\
\text { no. }\end{array}$} & \multirow{2}{*}{$\begin{array}{l}\text { Agel } \\
\text { gender }\end{array}$} & \multirow{2}{*}{$\begin{array}{l}\text { Pain } \\
\text { relief }\end{array}$} & \multirow{2}{*}{$\begin{array}{l}\text { Ulcer size } \\
\text { reduction }\end{array}$} & \multicolumn{4}{|c|}{ Improvement of blood flow* } & \multirow{2}{*}{ Events } \\
\hline & & & & $S T$ & $S P P$ & $A B I$ & Angio & \\
\hline 1 & $65 / M$ & + & & + & \pm & + & - & \\
\hline 2 & $64 / F$ & + & + & + & \pm & + & + & \\
\hline 3 & $66 / M$ & + & + & - & + & + & - & Minor retinal bleeding \\
\hline 4 & $64 / F$ & + & - & + & + & - & - & \\
\hline 5 & $64 / M$ & + & & + & + & + & + & Toe amputation \\
\hline 6 & $54 / M$ & - & + & + & - & - & - & \\
\hline 7 & $68 / F$ & + & & + & - & + & + & \\
\hline
\end{tabular}

ST, skin temperature; SPP, skin perfusion pressure ( \pm : means $0 \sim+10 \mathrm{mmHg}$ or different findings between toes and lower legs); ABI, ankle-brachial index; Angio, angiography.

*All parameters were estimated at 6 months after the procedure, except angiography.
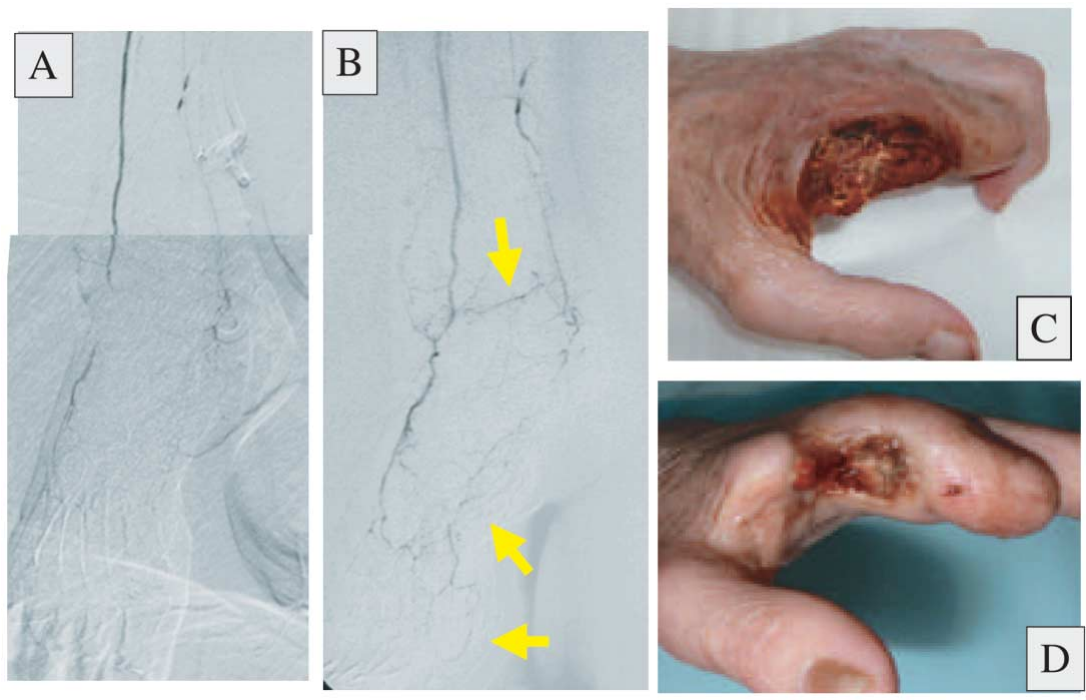

Fig 4. Angiographic improvement is shown in the comparison between before (A) and 1 month after treatment (B) in case No.7. New collateral vessels and dorsal metatarsal arteries can be seen (arrow). Clinical improvement was seen by comparison between before $(\mathrm{C})$ and 6 months after the treatment (D) in case No.2. Her ulcer after $2^{\text {nd }}$ finger amputation worsened against any medical treatment and no bleeding was seen, which improved after the treatment. Ulcer size decreased from $50 \times 30 \mathrm{~mm}$ to $12 \times 8 \mathrm{~mm}$ at 6 months after the treatment.

tim or filgrastim) by subcutaneous injection for 4 days, autologous PBMNCs were harvested using a Spectra cell separator (Cobe, Tokyo, Japan). We checked the number of leukocytes every day during administration of G-SCF, and if leukocyte count before administration of G-CSF was $>50,000 \mu \mathrm{l}$, administration of G-CSF was reduced to $2.5 \mu \mathrm{g}$. $\mathrm{kg}^{-1} \cdot$ day $^{-1}$, and if over $75,000 \mu \mathrm{l}$, administration of G-CSF was stopped. After separating PBMNCs and checking the number of $\mathrm{CD}_{3} 4^{+}$cells, patients were injected with $0.5 \mathrm{ml}$ of mononuclear fluid in each of 50-100 sites in the muscle of both ischemic limbs, under epidural anesthesia on a single day. Injections were placed $1 \mathrm{~cm}$ apart, using a $25 \mathrm{~g}$ needle.

\section{Statistical Analysis}

Clinical data were analyzed with unpaired 2 group t-tests and nonparametric Mann-Whitney tests as appropriate. Results are presented as means \pm SD. Analyses were performed with JMP 5.0.1J software (SAS Institute, Cary, NC, USA). P-values below 0.05 were considered to be statistically significant.

\section{Results}

In most patients, skin temperature in the lower legs and toes improved at each observational point, even at 1 and 2 weeks after the treatment (Fig 1). The peak elevations of skin temperature were observed at 6 months after the treat- ment (end of the observation period) in the lower legs $\left(+1.18 \pm 1.08^{\circ} \mathrm{C}\right)$ and at 3 months in the toes $\left(+1.33 \pm 0.92^{\circ} \mathrm{C}\right)$. The SPP in the ankles also increased early after treatment (Fig 2); however, the SPP in the toes did not show a significant change. ABI also improved gradually after the treatment (Fig 3). The peak elevation of ABI was seen at the end of the observation period (ie, 6 months: $+0.11 \pm 0.15$ ) and ABI improved more than 0.10 in 5 of 7 cases; however ABI did not show a significant change.

Ulcer size improved in 3 of 4 patients (Table 2). Ischemic leg pain improved in 6 of 7 patients within 2 weeks (Table 3 ), and continued to the end of the observation period. Angiographic improvements were seen in 3 of 7 patients at 1 month after the treatment (Fig 4). After treatment, bodily pain on the HR-QOL improved with significance $(\mathrm{p}<0.01)$ and no HR-QOL parameter got worse after the treatment (Fig 5). We could not find any relationship between the number of $\mathrm{CD} 34^{+}$cells injected and clinical outcomes. There was no patient who had worsened ASO symptoms or ulcer size, new cardiovascular events, or other serious complications. One patient with moderate proliferative diabetic retinopathy had minor retinal bleeding 1 week after the treatment, which recovered within 1 month without functional loss. One patient with progressive toe gangrene (patient No.5) before transplantation required toe amputation despite treatment. 


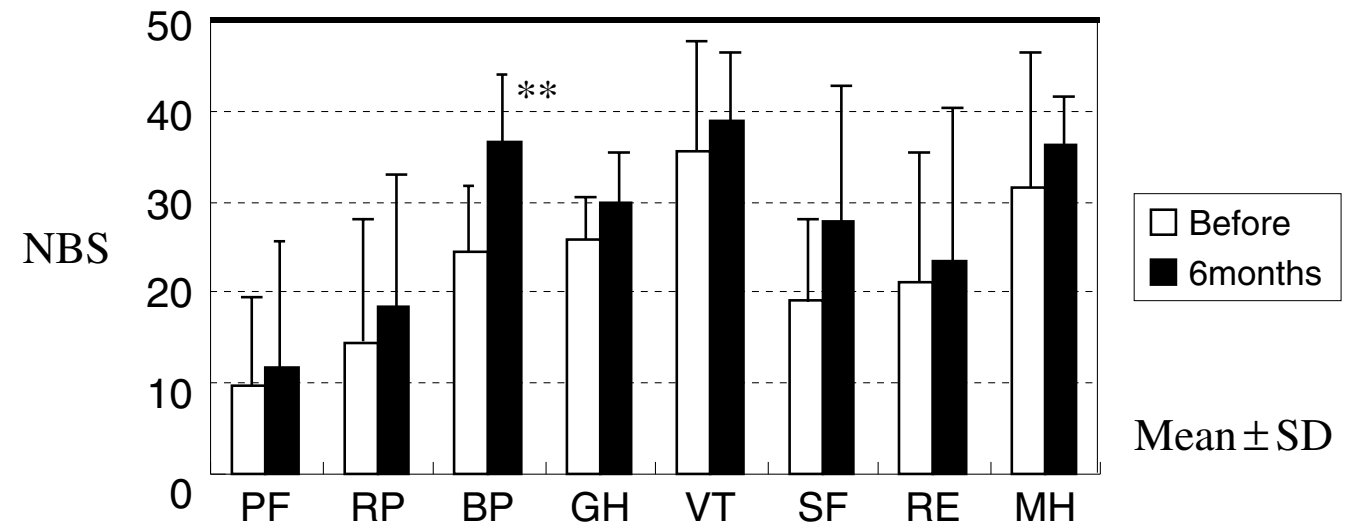

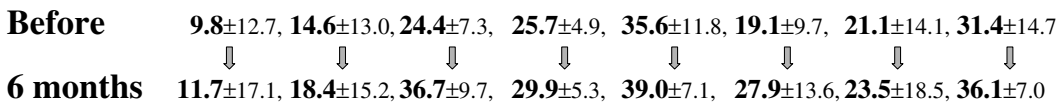

Fig 5. All health-related quality of life (HR-QOL) parameters before the treatment were significantly lower than for the Japanese standard population; physical functioning (PF), physical role, and social functioning (SF) were all less than 20. These data clearly show how arteriosclerosis obliterans patients with diabetes mellitus on dialysis have poor HR-QOL, and how peripheral blood mononuclear cell (PBMNC) transplantation improved their HR-QOL, especially bodily pain (BP) $(\mathrm{p}<0.01)$. * $\mathrm{p}<0.01$. RP, role physical; GH, general health perceptions; VT, vitality; RE, role emotional; MH, mental health; NBS, norm-based scoring.

\section{Discussion}

The number of patients with ischemic limbs is increasing, especially those with DM on HD. These patients represent one of the highest risk groups for peripheral arterial disease and their treatment options are often limited to amputation. The poor outcomes of these patients may be due to vascular calcification and poor physical status. Many new angiogenetic therapeutic methods using mononuclear cells and recombinant gene therapy for ischemic limbs have been recently reported and shown to have beneficial effects. Treatment with bone marrow mononuclear cells (BMMNCs) was reported to promote angiogenesis in the diabetic foot ${ }^{2}$ and Rehman and Tateno reported that PBMNCs produce more angiogenic factors and cytokines than BMMNCs, which may also make them a more useful source.,7 Our study also showed beneficial therapeutic effects for patients with DM on HD, which may imply an advantage of PBMNC vs BMMNC transplantation or may be related to differences in our patients' conditions. Because HD patients often have poor physical status and hypocellular bone marrow, autologous PBMNCs transplantation may be a better option because the easy blood access is less invasive. GCSF has been reported to have some beneficial therapeutic effects for ischemic limbs? In the present study, only the Fontaine IV patient with progressive gangrene and infection went on to amputation. Our other chronic Fontaine IV cases with ulcers, and the Fontaine III cases, each had a good clinical course after the therapy. Based on our data and the literature, PBMNC transplantation may be effective for chronic Fontaine III and IV ischemic limbs without infection or gangrene, although this study has the limitation of not being a control study. One patient with moderate proliferative diabetic retinopathy had minor retinal bleeding 1 week after the treatment. The oculist reported that this event was probably part of the natural course, but we can not deny the possibility that it was caused by the treatment.

No previous reports have shown the long-term effect of autologous PBMNCs transplantation nor have such effects been studied in HD patients with DM. Our data suggest that PBMNC transplantation improves leg ischemia and pain for at least 6 months and with few complications, even in such high-risk patients as those with DM on HD. In cases where amputation is required, pre-operative angiogenic therapy might prove beneficial for surgical wound healing. This therapy may also decrease the required amputation level, which often results in better QOL.

This is the first study in which HR-QOL was measured in ischemic limb patients with DM on HD. We also evaluated the effect of PBMNC transplantation on certain aspects of the HR-QOL. All HR-QOL parameters before the treatment were significantly lower than in the Japanese standard population; physical functioning, physical role, and social functioning were all less than 20 . These data clearly show how ASO patients with DM on HD have poor HR-QOL, and how PBMNC transplantation improved their HR-QOL, especially bodily pain.

It is still unknown whether there is a relationship between the number of $\mathrm{CD} 34^{+}$cells injected and potential improved angiogenic effects. In our study, we did not find a relationship between outcome and the number of CD34+ cells injected. For example, patient No.2, who received 100 fewer CD34+ cells than patient No.5, had a much bigger improvement in blood flow and ulcer condition than patient No.5. Saigawa et $\mathrm{al}^{9}$ and Ishida et $\mathrm{al}^{4}$ reported that there is a positive relationship between these factors, but Kinnaird et al ${ }^{10}$ and Rehman et $\mathrm{al}^{6}$ reported that this benefit was related to the level of angiogenic factors produced not merely the number of cells. By examining human microvascular endothelial cells, Rookmaaker et al reported that CD34- cells can induce migration of $\mathrm{CD} 34^{+}$cells to the endothelium because they observed little new angiogenesis and no recruitment to endothelium when CD34 cells were used alone.11 Our results support this hypothesis. CD34- cells might also influence angiogenesis and have therapeutic effects.

In the present study, most patients showed peripheral blood flow improvement within 1 or 2 weeks, with continued effects over 6 months. This early improvement suggests the 
effects of cytokines after the procedure, because it is too early for significant angiogenesis to have occurred. The later, persistent effects might be because of angiogenesis, as 6 months is likely too long to sustain an acute inflammatory response. Our results suggest the hypothesis that most of the angiogenic effects are related to such angiogenic factors as interleukin (IL)- $\mathbb{\beta}$, PDGF, and IL-812-15

Therapeutic angiogenesis is an important future therapeutic target for cardiovascular and peripheral ischemic diseases. Our findings suggest long-term effects of autologous PBMNCs transplantation, not only on clinical data but also on QOL, for severe ischemic limb disease, even in diabetic patients on HD who comprise one of the highest risk groups, without serious complications.

\section{Acknowledgments}

We thank our colleagues Drs Shigemoto Nakanishi, Yoshihiro Naruse, Akiko Maehara (Cardiovascular center, Toranomon Hospital), and Mayumi Okada (Department of anesthesiology) for their helpful advice.

\section{References}

1. Second European Consensus Documentation on Chronic Critical Leg Ischemia. Circulation 1991; 84(Suppl IV): IV-1-IV-26.

2. Tateishi-Yuyama E, Matsubara H, Murohara T, Ikeda U, Shintani S, Masaki $\mathrm{H}$, et al. Therapeutic angiogenesis for patients with limb ischemia by autologous transplantation of bone-marrow cells: A pilot study and a randomized controlled trial. Lancet 2002; 360: 427-435.

3. Huang PP, Li SZ, Han MZ, Xiao Z, Yang R, Han CZ. Autologous transplantation of granulocyte colony stimulation factor- mobilized peripheral blood mononuclear cells improves critical limb ischemia in diabetes. Diabetes Care 2005; 28: 2155-2160.

4. Ishida A, Ohya Y, Sakuda H, Ohshiro K, Higashiuesato Y, Nakaema $\mathrm{M}$, et al. Autologous peripheral blood mononuclear cell implantation for patients with peripheral arterial disease improves limb ischemia. Circ J 2005; 69: 1260-1265.

5. Fukuhara S, Suzukamo Y. Manual of SF-36v2, Japanese version.
Kyoto: Institute for Health Outcomes \& Process Evaluation Research, 2004.

6. Rehman J, Li J, Orschell CM, March KL. Peripheral blood "endothelial progenitor cells" are derived from monocyte/macrophages and secrete angiogenic growth factors. Circulation 2003; 107: $1164-$ 1169.

7. Tateno K, Minamino T, Miyauchi H, Kunieda T, Komuro I. Application of hematopoietic cells to therapeutic angiogenesis. Curr Pharm Des 2006; 12: 557-563.

8. Arai M, Misao Y, Nagai H, Kawasaki M, Nagashima K, Suzuki K, et al. Granulocyte colony-stimulating factor: A noninvasive regeneration therapy for treating atherosclerotic peripheral artery disease. Circ J 2006; 70: 1093 - 1098.

9. Saigawa T, Kato K, Ozawa T, Toba K, Makiyama Y, Minagawa S, et al. Clinical application of bone marrow implantation in patients with arteriosclerosis obliterans, and the association between efficacy and the number of implanted bone marrow cells. Circ J 2004; 68: $1189-$ 1193.

10. Kinnaird T, Stabile E, Burnett MS, Shou M, Lee CW, Barr S, et al. Local delivery of marrow-derived stromal cells augments collateral perfusion through paracrine mechanisms. Circulation 2004; 109: $1543-1549$.

11. Rookmaaker MB, Verhaar MC, Loomans CJ, Verloop R, Peters E, Westerweel PE, et al. CD34+ cells home, proliferate, and participate in capillary formation, and in combination with CD34- cells enhance tube formation in a 3-dimensional matrix. Arterioscler Thromb Vasc Biol 2005; 25: 1843-1850.

12. Kamihata H, Matsubara H, Nishiue T, Fujiyama S, Amano K, Iba O, et al. Improvement of collateral perfusion and regional function by implantation of peripheral blood mononuclear cells into ischemic hibernating myocardium. Arterioscler Thromb Vasc Biol 2002; 22: $1804-1810$.

13. Qin SL, Li TS, Takahashi M, Hamano K. In vitro assessment of the effect of interleukin-1 beta on angiogenic potential of bone marrow cells. Circ J 2006; 70: 1195-1199.

14. Steed DL. Clinical evaluation of recombinant human platelet-derived growth factor for the treatment of lower extremity ulcers. Plast Reconstr Surg 2006; 117: 143-149.

15. Li A, Varney ML, Valasek J, Godfrey M, Dave BJ, Singh RK. Autocrine role of interleukin-8 in induction of endothelial cell proliferation, survival, migration and MMP-2 production and angiogenesis. Angiogenesis 2005; 8: 63-71. 